\title{
Território, cooperação e inovação: um estudo sobre o Arranjo Produtivo Pingo D'água
}

\author{
Keuler Hissa Teixeira ${ }^{1}$ \\ Jair do Amaral Filho ${ }^{2}$ \\ Ruben Dario Mayorga ${ }^{3}$ \\ Maria Irles de Oliveira Mayorga ${ }^{4}$
}

Resumo: Vários estados e municípios brasileiros já adotam programas de investimento direcionados aos arranjos produtivos locais (APL's) constituídos por micros, pequenas e médias empresas. No entanto, a maioria dos estudos sobre APL's tem dado pouca importância a arranjos produtivos locais de natureza agrícola. Este estudo se propõe analisar o APL, de agricultura irrigada, Pingo d'Água em Quixeramobim, Ceará. Os dados utilizados neste trabalho são de origem primária e secundária obtidos por meio de pesquisa bibliográfica, documental, estudo de caso e pesquisa de campo. Os resultados foram verificados a partir de uma análise tabular e descritiva. No arranjo analisado, verificou-se o envolvimento de vários parceiros de diversos segmentos com maior ou menor grau de participação, constituindo instrumentos importantes na introdução de inovações de produto, processo e organizacional, criando novas competências e obtenções de vantagens competitivas. Porém, observou-se a existência de obstáculos relacionadas à inexistência de centros de trei-

${ }^{1}$ Doutorando em Economia pela Universidade Federal de Pernambuco (UFPE/PIMES). keulerht@yahoo.com.br.

${ }^{2}$ Doutor em Economia, Professor Titular em Desenvolvimento Econômico do Departamento de Teoria Econômica - DTE da Universidade Federal do Ceará - UFC e Membro da REDESIST. amarelo@fortalnet.com.br

${ }^{3} \mathrm{PhD}$. Prof. Adjunto do Dep. de Economia Agrícola da Universidade Federal do Ceará. dario@ufc.br

${ }^{4}$ Economista, Ph.D e Professora Adjunta do Dep. de Economia Agrícola da Universidade Federal do Ceará. irles@ufc.br 
namento adequados para qualificação dos produtores, ausência de laboratórios de pesquisa e falta de linhas de crédito mais adequadas à realidade dos produtores. Apesar destes entraves, pôde-se concluir que existem alguns ganhos de eficiência coletiva originados por esta aglomeração produtiva, sendo este arranjo uma prova de que, com um pouco de organização social e vontade dos atores locais, é possível mudar a realidade desfavorável das famílias que vivem da agricultura no sertão semi-árido cearense.

Palavras-chave: Arranjo Produtivo Local, inovação, capital social.

\section{Classificação JEL:}

Abstract: Several states and Brazilian countries already have adopted investment programs to the local productive arrangements (LPA's) that involves by micro, small and median companies. However, most of the studies on LPA's has given little attention to the local productive arrangements of agricultural nature. This study intends to analyze the LPA, of irrigated agriculture, called "Drop of water" in Quixeramobim, Ceará. It was used primary and secondary data that were obtained through bibliographical and documental researches, case study and field researches. The resulted were verified through of tabular and descriptive analyze. Inside the arrangement analyzed we could verify the involvement of several partners' from different segments that participated in higher or lower degree. This involvement of several partners' establishing important instruments for introduction of innovations of product, process and organizational creating new competences and gains competitive advantages. However, it was verified the existence of obstacles related to the inexistence of inappropriate training centers for qualification of the producers, absence of research laboratories and lack of more appropriate credit lines adjusted producer's reality. In spite of these problems, we can conclude that there was gain of resulted from the collective efficiency that was created by this productive gathering. This arrangement is a proof that with some social organization of the local actor's will be possible to change the difficult reality of the families that earn from their income agriculture in the zone semi-arid of the Ceará. 
Key words: Local Productive Arrangement, innovation, social capital.

\section{JEL Classification:}

\section{Introdução}

Atualmente, vários estudiosos tentam explicar uma correlação entre bom desempenho competitivo das firmas e à proximidade geográfica das empresas, bem como sua própria relação com a dimensão territorial na qual estão inseridas. Enfatizando que as empresas devem ser analisadas considerando suas relações entre elas próprias e instituições, entre o espaço geográfico definido e entre as características do ambiente em que estas se encontram, e não mais de forma isolada (CASSIOLATO e SZAPIRO, 2003).

Um dos alvos de interesse e estudo no Brasil entre estes analistas tem sido o conceito de arranjos produtivos locais - APL's. Porém, Amaral Filho et al. (2002), destaca a pouca importância dada a arranjos produtivos locais de natureza agrícola, formados por pequenos agricultores familiares cuja produção é voltada principalmente para o mercado local e regional. Apesar disto, nos últimos anos, estes tipos de arranjos, com segmento na agricultura irrigada, possuem uma importância significativa na economia do Nordeste ${ }^{5}$, pois, têm demonstrado expressiva capacidade de geração de inovações, emprego e renda.

Dado o exposto acima, este trabalho pretende-se preencher, exatamente, esta lacuna, examinando um pouco mais de perto o caso do arranjo produtivo Pingo d'água, localizado no Vale do Forquilha, em Quixeramobim, Ceará. O referido arranjo é formado por um grupo de pequenos agricultores familiares, tendo sido caracterizado como um caso inovador e bem-sucedido.

O trabalho desenvolveu-se a partir de alguns procedimentos pré-definidos, quais sejam: o levantamento de informações gerais sobre o arranjo, referências bibliográficas, dados estatísticos e outros, bem como através de visitas à área para melhor conhecimento dos principais aspectos ligados a produção, estágio tecnológico, estrutura de apoio. Para

${ }^{5}$ Para maiores detalhes ver Amaral Filho (2004). 
isso, foram efetuadas entrevistas estruturadas com produtores ${ }^{6}$. Os resultados foram verificados a partir de uma análise tabular e descritiva.

A escolha do tamanho da amostra ocorreu mediante a viagem realizada no final de setembro de 2003, com o intuito de conhecer e levantar o número de produtores envolvidos no arranjo produtivo Pingo d'Água a serem entrevistados. Considerando o número de produtores que integram o arranjo, na época da pesquisa, 29 produtores, optamos pela realização de um censo, isto é, o levantamento total da população a ser entrevistada. Porém foram entrevistados 23 destes produtores, representando uma amostra de $79,31 \%$ da população total ${ }^{7}$.

Além desta seção, o trabalho foi sistematizado da seguinte maneira: a seção 2 faz uma breve revisão do marco conceitual relevante para ilustrar a importância da relação entre a proximidade geográfica das empresas traduzida em aglomerações produtivas, com a dimensão territorial e destas com o processo de capacitação inovativa e competitiva. Nesse contexto, será abordado o conceito de arranjos produtivos locais. Na seção 3, será enfocado o arranjo produtivo e as evidências sobre os processos interativos de inovação e aprendizado, cooperação e governança. Finalmente, na seção 4, são apresentadas as observações conclusivas.

\section{Aspectos conceituais}

\subsection{Arranjos e sistemas produtivos locais-ASPL's}

A Rede de Pesquisa em Sistema Produtivos e Inovativos Locais $\left(\right.$ REDESIST $^{8}$ desenvolveu por questão de adaptação para o Brasil os

\footnotetext{
${ }^{6}$ A estrutura do questionário foi elaborada com a mesma base conceitual e metodológica desenvolvida nos diversos trabalhos da REDESIST, sobre os ASPL's, sendo este questionário aplicado nas pesquisas de campo realizadas pela referida rede.

${ }^{7}$ No período da pesquisa de campo, a condição de saúde de um produtor e ausência de outros, em razão de viagens, foram os motivos que não permitiram que a aplicação do questionário fosse realizada a todos os produtores do arranjo.

${ }^{8}$ A REDESIST é uma rede de pesquisa de caráter interdisciplinar, formalizada desde 1997, sediada no Instituto de Economia da Universidade Federal do Rio de Janeiro. Desta rede, participam diversas universidades e institutos de pesquisa no Brasil e no Exterior, promovendo importantes estudos sobre o papel dos arranjos e sistemas produtivos locais (ASPL's) na construção do processo de desenvolvimento econômico (REDESIST, < http://www.ie.ufrj.br/redesist. > acesso: Out.2003).
} 
conceitos de arranjos e sistemas produtivos locais (ASPL's), focalizando um conjunto especifico de atividades econômicas que possibilitem e privilegiem a análise de interações, particularmente aquelas que levam à introdução de novos produtos e processos. Assim, a ênfase em ASPL's privilegia a investigação das relações entre conjuntos de empresas e destes com outros atores; dos fluxos de conhecimento, em particular, em sua dimensão tácita; das bases dos processos de aprendizado para as capacitações produtivas, organizacionais e inovativas; da importância da proximidade geográfica e identidade histórica, institucional, social e cultural como fontes de diversidades e vantagens competitivas.

Segundo o estudo da REDESIST, os arranjos produtivos locais (APL's) são definidos como aglomerações territoriais de agentes econômicos, políticos e sociais - com foco em um conjunto específico de atividades econômicas - que apresentam vínculos mesmo que incipientes. Por outro lado, os sistemas produtivos e inovativos locais (SPL's) são aqueles arranjos produtivos em que interdependência, articulação e vínculos consistentes resultam em interação, cooperação e aprendizagem, como potencial para originar o incremento da capacidade inovativa endógena, da competitividade e do desenvolvimento local.

A diferença de um APL para um SPL é que o primeiro possui estrutura pouco desenvolvida, tendo a informalidade como uma característica predominante na maioria dos casos. Outro ponto a ser destacado é que em grande parte os APL's surgiram praticamente de um improviso dos produtores ou das demandas da região; as inovações, normalmente, possuem um caráter incremental e, a mão-de-obra é pouco qualificada, sendo seu treinamento prático pouco usual. Geralmente, um arranjo produtivo é composto por micro e pequenas empresas, e cuja capacidade/formação gerencial/administrativa dos donos/administradores é baixa ou não há quase nenhuma (SOUZA, 2003).

Apesar da fragilidade dos arranjos produtivos, conforme Amaral Filho et al. (2002), é preferível que as empresas se encontrem localizadas dentro dessas estruturas do que atuando de forma isolada. Estes autores afirmam ainda que as micros, pequenas e médias empresas (MPME's), ao atuarem de maneira isolada, reproduzindo a forma de funcionamento de grandes empresas, as primeiras ficam 
incapazes de gerar economias de escala, aliás, uma das principais dificuldades que as persegue. Essas economias estão associadas a elevados volumes de produção, características das grandes empresas e não das MPME's, ficando relegadas à condição de unidades de produção ineficientes.

Portanto, quando as MPME's se organizam em forma de APL's, abre-se a possibilidade de torná-las tão competitivas quanto as grandes empresas, mas, para isso, é preciso que essas aglomerações de MPME's dentro de um APL's adicionem e transacionem as vantagens existentes nas grandes empresas, tais como: tecnologia, logística, transferência de informações e do conhecimento. Além disso, alcançam economias de escala, o que para uma pequena empresa isolada se torna praticamente inviável (AMARAL FILHO et al., 2002). Diante de tais evidências, ainda que as estruturas produtivas das empresas envolvidas nos APL's sejam caracterizadas como incipientes em seu nível de organização, esse ambiente permite interações entre os atores e com o entorno, criando, com isso, uma atmosfera favorável para o alcance de ganhos coletivos (AMARAL FILHO et al., 2002).

Vale lembrar, entretanto, segundo Amorim et al. (2004), que a formação dos arranjos produtivos locais, mesmo contribuindo em avanço em relação ao funcionamento disperso e isolado das empresas e outros agentes, não deve ser contemplada como objetivo final, mas deve ser uma ponte de ligação para formas de organização superior, mais sistêmica e com maior nível de articulação entre os agentes, ou seja, os sistemas produtivos locais.

De acordo com Albagli e Brito (2003), em pesquisas realizadas pela REDESIST, mostram também que a formação de arranjos e sistemas produtivos locais encontra-se, geralmente, associada a trajetórias históricas de construção de identidades e de formação de vínculos territoriais (regionais e locais), a partir de uma base social, cultural, política e econômica comum; e que estes são mais propícios a desenvolverem-se em ambientes favoráveis à interação, à cooperação e à confiança entre os atores. A ação de políticas tanto públicas como privadas pode contribuir para fomentar e estimular tais processos históricos de longo prazo. 


\subsection{Características dos arranjos produtivos locais}

Pode-se afirmar que não existe uma fórmula específica para criação ou desenvolvimento de APL's, pois há aspectos característicos para cada tipo de arranjo que variam de acordo com a região na qual os agentes destes arranjos estão envolvidos, ou seja, as diferenças estão inerentes à dinâmica interna de cada um deles, entretanto, é pertinente dizer da existência de traços comuns entre eles. Amaral filho (2002) afirma que em todos os casos exitosos de organização coletiva de MPME's verificou-se a presença de quatro elementos estruturantes comuns que se apresentaram também de maneira articulada. Estes elementos, de acordo com o mesmo autor, referem-se ao capital social, estratégias coletivas de organização da produção, estratégias coletivas de mercado e articulação político-institucional.

Quanto ao capital social, refere-se a um fator intangível por natureza, representando um acúmulo de compromissos sociais consolidados pelas interações sociais em uma determinada localidade. Por sua vez, este capital social serve de apoio a outro componente, conhecido como estratégia coletiva de organização da produção. Esta estratégia se relaciona com as decisões coordenadas, entre os produtores, no que se refere a quem vai produzir, o que produzir e como produzir. E é por meio desta estratégia que a aglomeração das pequenas empresas determina seu poder em relação às grandes empresas, por meio da equivalência da vantagem em relação à escala da compra dos insumos, do uso de máquinas e equipamentos, da produção em geral etc. Também, é por meio da estratégia coletiva de organização da produção que se revela e se processa a aprendizagem coletiva, fonte das inovações e da competitividade.

O terceiro elemento, conforme Amaral Filho (2002) está direcionada à estratégia coletiva de mercado. Esta também está voltada para as ações coordenadas e convergentes entre os produtores. Vale ressaltar que a estratégia coletiva de organização da produção não teria importância caso não existisse uma estratégia também coordenada e coletiva para a conquista e manutenção dos mercados. Isto decorre em razão de que os mercados compradores, além de serem formados por grandes players, são também condicionados por 
grande escala. Sem uma estratégia comum entre os produtores, fica difícil para a pequena empresa superar esses obstáculos, pois as pequenas empresas veriam reduzidos os ganhos conseguidos nas economias de escala alcançados nas esferas da compra dos insumos e na realização da produção.

O último integrante está voltado para a articulação político-institucional, também decorrida do capital social. Este elemento é o instrumento pelo qual o arranjo produtivo se articula com instituições públicas e privadas responsáveis pelas políticas públicas, e com as organizações privadas de apoio às pequenas empresas. As evidências revelam que, quanto mais capital social acumulado dentro de num determinado núcleo ou aglomeração de empresas, melhor e mais eficiente será a articulação com as organizações e instituições.

\section{Perfil do Arranjo Produtivo Pingo D'água}

\subsection{O território, a origem e trajetória de desenvolvimento}

O arranjo está localizado no Vale do Riacho do Forquilha, de $30 \mathrm{~km}$ de extensão, distrito de Manituba, e o mesmo está composto por produtores pertencentes a oito comunidades, quais sejam, Campina, Boa Vista, São Bento, Várzea do Meio, Forquilha, Trapiazeiro, Lagoa Cercada e Limeira. Fora do Vale, mas inserido no referido arranjo, está a comunidade de Encantado. Contrastando com esse quadro, o Vale do Forquilha como um todo reúne 17 comunidades abrigando mais de mil famílias de pequenos produtores familiares. Às margens do Riacho do Forquilha encontram-se as terras mais férteis, formadas por aluviões, com faixas que vão até 250 metros de largura, onde está sendo desenvolvida a agricultura irrigada. O Vale encontra-se no Município de Quixeramobim, Sertão Central do Ceará, distante 200 km da capital Fortaleza.

Entretanto, a região do referido vale, tradicionalmente, tinha como base as culturas de sequeiro e as conhecidas culturas de subsistências. A área é parte do chamado polígono das secas do Nordeste. As famílias ao longo do vale do Forquilha enfrentavam a falta de água para consumo humano e animal, dependendo muitas vezes de carros-pipa mas, desde 1998, a região começou a mudar esta realidade. Esta transforma- 
ção teve início com a implantação do Projeto Pingo d'Água que ocorreu, segundo Amaral Filho (2004), mediante convênio de cooperação firmado entre as Universidades Francesas Ecole National d'Ingénieurs des Techiniques de Hoticulture et du Paysage (ENITHP) e Université Francois Rabelais (UFR), a Prefeitura de Quixeramobim, Ceará e Universidade Estadual do Ceará (UECE) ${ }^{10}$. A princípio, o objetivo principal deste convênio era propiciar o acesso à água de boa qualidade às comunidades rurais, utilizando uma tecnologia simples de perfuração de poços tubulares rasos nas áreas de aluvião ${ }^{11}$ (SCHOMMER, 2002).

Verificando-se a qualidade da água e a vazão dos poços perfurados, a equipe do projeto percebeu que as potencialidades iam além do abastecimento de água para consumo, entendendo que era possível partir para a produção e para a geração de renda, por intermédio da agricultura irrigada (ARAÚJO e FUCK JÚNIOR, 2000). A origem da formação do arranjo produtivo local de agricultura irrigada surge com intuito de superar a própria desconfiança dos produtores em relação a estes novos métodos de produção, além da ausência vocacional e histórica desta atividade em suas vidas, configurada pela mentalidade enraizada nos métodos tradicionais de plantio com base nas culturas de sequeiro e subsistência, muito comum no sertão cearense.

\subsection{Estrutura produtiva e a estratégia de comercialização}

O Arranjo Produtivo Pingo D'água é composto por 29 pequenos produtores agrícolas familiares que exploram a agricultura irrigada com base na produção de frutas e hortaliças, além de desenvolverem ati-

\footnotetext{
${ }^{9}$ Segundo o Sr. Carlos Simão, Secretário de Desenvolvimento Econômico de Quixeramobim, a origem deste nome surgiu em tom de chacota daqueles que não acreditavam no sucesso deste projeto, alegando que não se conseguiria obter a vazão de água esperada pela equipe do projeto. Estes incrédulos diziam: “...será apenas um pingo d'água... um passarinho bebe sozinho esta água”, comentou o Secretário.

${ }^{10}$ Esta para viabilizar o repasse de recursos às universidades conveniadas. Mais tarde, em 2001, o convênio científico foi renovado entre e a Universidade Comunitária de Quixeramobim (UNICENTRO).

${ }^{11}$ De acordo com Schommer (2002), nessas áreas, quando há incidência de chuvas, uma parte da água dos rios e riachos é acumulada em lençóis subterrâneos próximos à superfície, em meio a um solo composto basicamente de areia e argila, onde permanece mesmo quando o leito fica seco na superfície.
} 
vidades complementares associadas à agricultura de sequeiro, pecuárias bovina e ovinocaprino em pequena escala, pequenos criatórios e produção de doces de leite e mamão. Observa-se, quanto ao porte ou tamanho, que todos os entrevistados são classificados como microprodutores ${ }^{12}$. Neste arranjo, são desenvolvidas principalmente as culturas de tomate, mamão, melão, maracujá e pimentão ${ }^{13}$, e os sistemas de irrigação praticados são microaspersão e gotejamento. As propriedades rurais variam de 5 ha a 30 ha, entretanto as áreas utilizadas na agricultura irrigada variam de 1 ha a 3 ha. No ano de 2003, dentro do arranjo produtivo, foram produzidos 3.940 caixas/ano de tomate, 18.374 caixas/ano de mamão, 2.405 caixas/ano de melão, 3.170 caixas/ano de maracujá, 1.195 caixas/ano de pimentão e 420 caixas/ano de goiaba.

De acordo com a pesquisa, os preços dos produtos são bastante variados com forte sazonalidade e muito suscetíveis às oscilações do mercado cearense. O valor total da produção no referido ano foi de R\$ 209.365,26 (Tabela 1). Deste valor, podemos deduzir uma renda mensal aproximadamente de $\mathrm{R} \$ 758,56$ para cada produtor. Esta renda gerada pelos produtores daquela localidade é praticamente despendida no mercado local, gerando emprego e renda, configurando-se como um elemento importante para inibir o êxodo rural e propiciar uma perspectiva mais otimista em relação ao futuro daquelas famílias.

O mercado consumidor é composto basicamente pelo mercado de Fortaleza, representado pela CEASA (Centrais de Abastecimento do Ceará S/A.), mercado local de Quixeramobim e o outro destino da produção refere-se aos mercados vizinhos. Dentre os mecanismos de comercialização, verificamos a existência de dois grupos de produtores que, dentro do arranjo, se uniram pela proximidade territorial e/ou por afinidades, sem nenhum contrato formal, criando estratégias de comercialização com focos de mercado diferentes, onde um grupo destina

${ }^{12}$ Conforme Campos e Nicolau (2003), a classificação utilizada para verificar o porte ou tamanho dos produtores foi definida de acordo com o número de pessoas ocupadas dentro dos empreendimentos, que são: a) micro - até 19; b) pequena - 20 a 99; c) média - 100 a 499 e d) 500 ou mais pessoas ocupadas.

${ }^{13}$ Segundo Amaral Filho (2004) pôde-se observar que, além das atividades com base na agricultura irrigada, os produtores desenvolvem atividades, embora complementares, associadas à agricultura de sequeiro, pecuária bovina e ovinocaprino em pequena escala, pequenos criatórios e produção de doces de leite e mamão. 
toda sua produção para o mercado de Fortaleza e outro abrange o mercado local e os vizinhos.

Tabela 1 - Valor da produção em $2003^{14}$

\begin{tabular}{c|c|c}
\hline Tipo de Cultura & Preço Médio por Caixa (R\$) & Valor da Produção (R\$) \\
\hline Tomate & 11,17 & $44.009,80$ \\
Mamão & 6,04 & $110.978,96$ \\
Melão & 6,40 & $15.392,00$ \\
Maracujá & 10,30 & $32.651,00$ \\
Pimentão & 5,30 & $6.333,50$ \\
Goiaba* & - & - \\
\hline \multicolumn{2}{c}{} & $\mathbf{2 0 9 . 3 6 5 , 2 6}$ \\
\hline
\end{tabular}

Fonte: Pesquisa de campo (2003)

* Em relação ao preço médio da goiaba não foi possível realizar o levantamento.

\subsection{Processo de aprendizagem coletiva e características das atividades inovativas}

Devido à falta de experiência e conhecimento em relação à exploração da agricultura irrigada, era de se esperar que uma das principais dificuldades estivesse relacionada à operação do empreendimento, tais como dificuldade em produzir com qualidade, à venda da produção.

A superação e a redução destes problemas foram reflexos dos processos de aprendizagem coletiva representada pelos cursos e treinamentos promovidos por instituições de apoio e capacitação dentro e fora do arranjo, desenvolvendo o conhecimento e habilidades desses produtores em relação à atividade incorporada. Estas ações vêm gerando um ambiente propício e dinâmico para os produtores na geração e propagação de conhecimento e inovações de produtos constatados pela transformação nas cestas de produtos desse grupo de produtores, passando do cultivo das culturas de sequeiro para culturas baseadas na agricultura irrigada. Associada a estas inovações, verificam-se as inovações de processo, no que diz respeito ao uso dos equipamentos, tais

${ }^{14}$ Multiplicando os valores encontrados nas estimativas relacionadas à quantidade produzida em 2003 com os preços médios (esses preços foram levantados diretamente com os produtores do arranjo.) das respectivas culturas, no mesmo ano. 
como microaspersores, mangueiras de gotejamento e também no que se refere ao manejo da terra, como, por exemplo, a utilização de técnicas de escalonamento das culturas.

Outro ponto interessante refere-se às mudanças nos conceitos e/ou práticas de marketing. Vale ressaltar aqui, que estamos considerando tais práticas como às ações implementadas pelos produtores no desejo de garantir a credibilidade de seus produtos, ao separar em caixas diferentes aqueles produtos de qualidade inferior, apresentando manchas ou deformações na aparência, assegurando desta forma um melhor preço para caixas com nível de qualidade superior e mantendo uma boa aparência em seus produtos para agradar os compradores. Ainda no campo das inovações organizacionais, constata-se que todos os produtores rurais entrevistados dentro do arranjo produtivo implantaram mudanças nas práticas de comercialização, baseando-se na cooperação, entre eles, onde até então esta prática ocorria de forma isolada.

Em função da introdução das inovações verifica-se um crescimento da produtividade, a ampliação da gama de produtos, ao crescimento da qualidade destes e redução do impacto sobre o meio ambiente, à abertura de novos mercados, principalmente, aqueles que conquistaram o mercado mais exigente, como o de Fortaleza. Para tanto, dado as exigências do mercado de Fortaleza esses produtores precisaram enquadrar-se nas regulações e normas padrão, para conquistar e manter-se no referido mercado. A Figura 1 nos mostra a estrutura dos processos de inovações, em seus diversos aspectos, incorporadas pelos produtores do arranjo produtivo Pingo d’Água, bem como os efeitos gerados por estas inovações, contribuindo para competitividades destes produtores.

De maneira geral, os produtores rurais organizados em forma de um arranjo produtivo local estão se apropriando e gerando conhecimento e inovações, tornando um processo fundamental para construção de novas competências e obtenções de vantagens competitivas; vantagens essas não ligadas às tradicionais, voltadas à economia de escala e a baixos custos de mão-de-obra e de matérias-primas, mas definida, fundamentalmente, pelo caráter inovador assumido pelo produtor. O papel de destaque no sentido da construção de vantagens competitivas, no entanto, é reservado ao caráter cooperativo das ações desenvolvidas mediante a mobilização dos atores integrantes do arranjo Pingo d’Água 
de modo que permitiu a participação, a ação conjunta (capital social), a coordenação e a governança das ações.

Figura 1 - Estrutura do processo de inovações e dos impactos gerados dentro do arranjo produtivo Pingo D’água

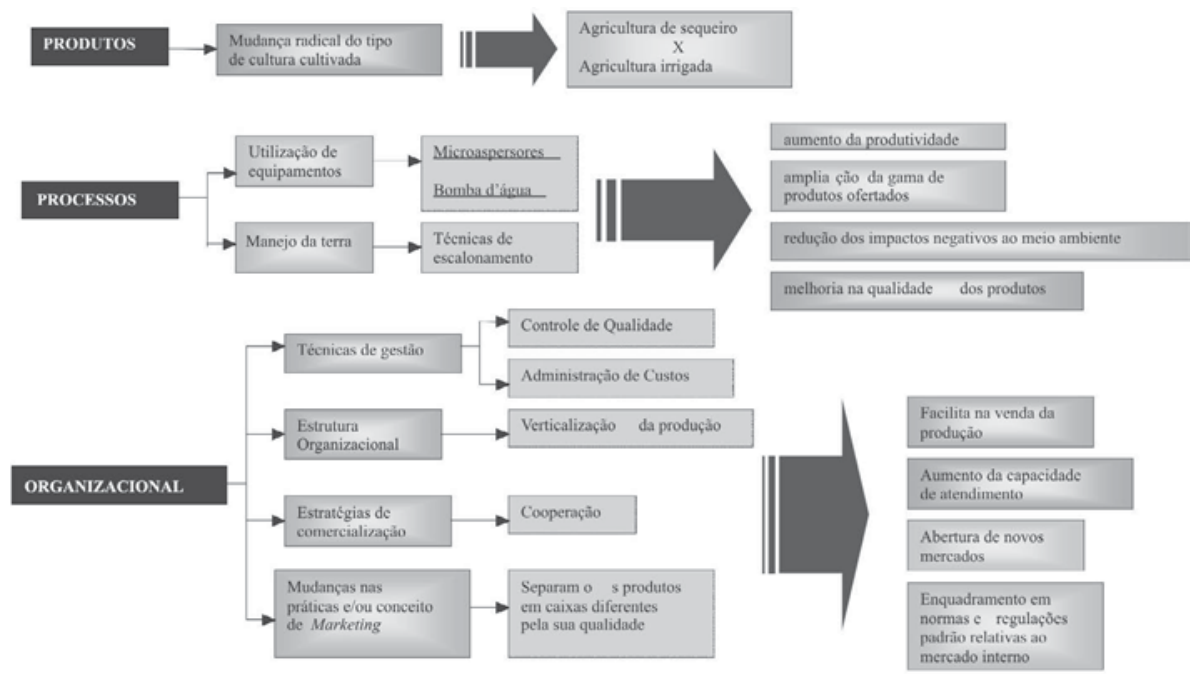

Fonte: Elaboração própria

\subsection{Perfil da cooperação entre os agentes do arranjo produtivo}

O arranjo produtivo Pingo d’Água nos remete à idéia de uma atividade econômica com base na agricultura irrigada, na qual, entre a produção e o consumo, vários agentes se relacionam, trocando informações sobre processo de produção, bem como as estratégias de comercialização, distribuição como alternativa para vencer o baixo nível de capitalização e promover a competitividade. Neste aspecto a forma mais importante de cooperação apontada pelos entrevistados foi a venda conjunta de produtos, já que eles se organizam em dois grupos, com focos de mercado diferentes, para vender a produção.

No entanto, estas estratégias coletivas de mercado, mesmo ocorrendo de maneira fracionada, têm permitido que a comercialização dos produtos aconteça sem obstáculos. Em segundo lugar, vêm as reivindicações. Sobre este aspecto é possível fazer algumas observações inte- 
ressantes, pois por meio dele foi que tudo começou, desde o momento em que as comunidades distribuídas no vale do Forquilha passaram a cobrar das autoridades competentes medidas para amenizar e solucionar os problemas causados pelas secas periódicas.

Outra forma apontada foi o desenvolvimento de produtos e processos, por meio da produção, em conjunto, de mudas dentro de uma estufa. Verificamos também que os produtores dividem com outros os resultados das experiências no cultivo de novos produtos, além de debaterem sobre as práticas de manejo dos equipamentos de irrigação e da terra.

Em ação conjunta à Prefeitura, que viabilizou todo o aporte necessário, os produtores destacam a participação conjunta em feiras e exposições na cidade de Fortaleza, (FRUTAL e a Irriga Ceará), bem como nas visitas realizadas aos Municípios de Brejo Santo, Guaraciaba do Norte, Aracati, São Benedito, todos localizados no Estado do Ceará, bem como a visita a Petrolina, em Pernambuco. Por último, a forma de cooperação menos importante é aquela associada à compra de insumos e equipamentos, que se dá de maneira atomizada. Sobre este tópico constatamos que aqueles produtores que obtêm baixos volumes na produção não possuem interesse em organizar-se em consórcio com produtores que alcançam níveis maiores, alegando conflitos quanto aos interesses destes volumes de insumos e matérias-primas necessárias.

No que tange à existência das formas de cooperação associadas à capacitação de recursos humanos e obtenção de financiamento, foi constatada a inexistência de qualquer forma de cooperação para estes aspectos. Para o primeiro aspecto, vimos no decorrer do trabalho a inexistência da percepção dos microprodutores quanto à qualidade da mão-de-obra como estratégia competitiva. Associada a esta característica, arraigada na cultura destes produtores, verificamos a ausência de ações conjuntas voltadas à capacitação dos recursos humanos.

Já para o segundo item, observamos que este comportamento foi reflexo da própria inflexibilidade das políticas de concessão de crédito dos bancos, ao perceberem que, apesar dos empréstimos serem de recursos voltados para estimular a agricultura familiar, seria necessário uma forma mais maleável nesta concessão a fim de estimular a cooperação dos produtores desta ponta do processo de formação do arranjo, 
por meio de concessões de empréstimos a grupos de produtores. Segundo os resultados da pesquisa, a estrutura da integração do arranjo produtivo demonstrou que todos os entrevistados desenvolvem algum tipo de interação com outros agentes produtivos (Figura 2).

Figura 2 - Formas de cooperação

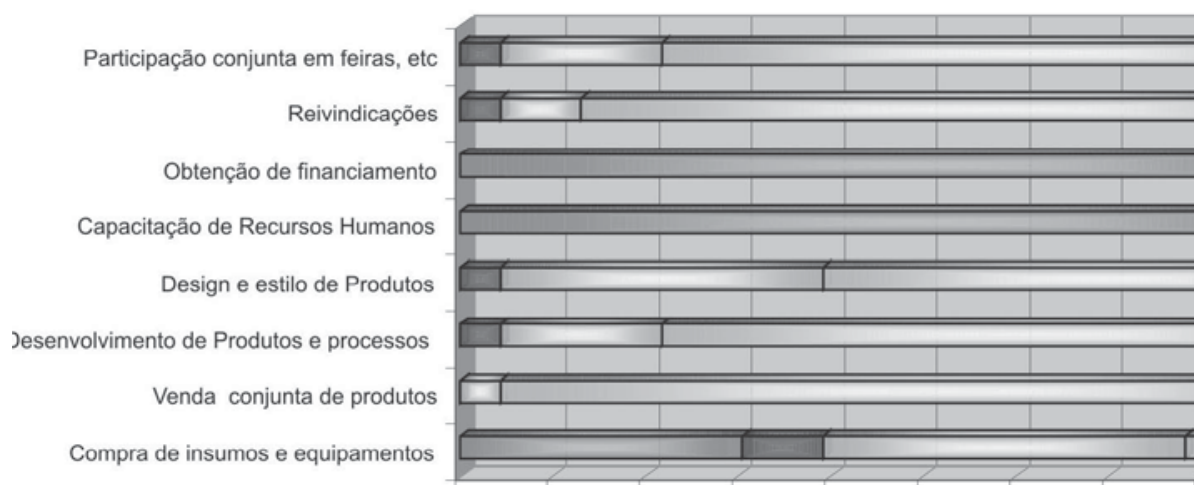

Fonte: Pesquisa de campo (2003)

Os resultados destas inter-relações refletem sobre a capacidade competitiva do produtor. Dentre estas, destacam-se as melhorias nas condições de comercialização por meio das ações conjuntas percebidas, a melhoria da qualidade dos produtos; outro resultado importante auferido dos produtores entrevistados está associado ao aperfeiçoamento dos processos produtivos, desenvolvimento de novos produtos, a melhoria na condição de fornecimento do produto, à introdução de inovações organizacionais, intrinsecamente relacionados aos itens anteriores, verificam-se os resultados das ações cooperativas associadas às novas oportunidades de negócios.

Portanto, o quadro geral observado na área, é um perfil onde predominam a troca de experiências, a prática de ações coletivas, no que diz respeito às questões ligadas à produção e à comercialização, e a tentativa de obter, de forma compartilhada, soluções para os problemas tecnológicos. As formas de cooperação no interior do arranjo podem ser expressas em parte por uma relação de movimento, não apenas no sentido de aproximação, trocas de experiência, mas, principalmente, pelas intenções voltadas às possibilidades de obtenção de lucro. 
A existência destes interesses faz com que estas pessoas se aproximem em direção a um lugar melhor para cooperação organizada, na forma de associações cooperativas, que criam elos de obrigações subjetivas com vistas à implementação de ações visando à concretização dos interesses comuns. Constatamos a contribuição da Associação local através “da promoção de ações cooperativas”, articulando-se com órgãos públicos e privados, além “da apresentação de reivindicações comuns” para expansão das atividades agrícolas e agroindustriais, desempenhando um papel crucial no processo de formação e desenvolvimento do arranjo.

Na opinião dos produtores entrevistados, a Associação dos Produtores dirige esforços importantes na "definição de objetivos comuns para o arranjo produtivo" e "no estímulo à geração de percepções de visões de futuro para ação estratégica" para o avanço tecnológico e mercadológico, atuando de maneira diversificada, envolvendo a geração de conhecimento e tecnologia, por meio "da promoção de ações dirigidas à capacitação tecnológica de empresas”. Sua transferência e difusão ocorrem por meio "da criação de fóruns e ambientes para discussão" desenvolvido pela referida Associação.

Vale enfatizar que este clima dentro do arranjo produtivo Pingo d'Água não é puramente presidido pelo altruísmo dos produtores e sim porque estes notaram e almejam as possibilidades de lucro, viabilizadas pelas ações cooperativas. Embora existam evidências claras sob as várias formas de cooperação entre os produtores, há de se ressaltar a presença de alguns tipos de concorrência entre os mesmos. No que diz respeito aos transportadores de mercadorias, representados por dois agentes locais, além da própria associação dos produtores, que reivindica para si essa função.

Destaca-se também a concorrência entre os produtores com visão comunitária e produtores com visão produtivista. Podemos afirmar que essa situação é reflexo da transformação da agricultura tradicional, sem intenção à acumulação do lucro, para a agricultura moderna, direcionada ao mercado e ao acúmulo do lucro e de ativos, sobretudo na forma de terra e equipamentos de irrigação. Em razão de não haver cotas, ou outorgas, limitando e racionalizando o uso individual da água, o seu crescimento desordenado poderá futuramente, desencadear conflitos mais explícitos entre os produtores (AMARAL FILHO, 2004). 


\subsection{A forma de coordenação e governança}

Vimos no decorrer do trabalho que o processo de formação do arranjo produtivo Pingo d'Água envolveu um salto de complexidade relacionada à interdependência entre diversos agentes (econômicos, políticos, institucionais e sociais) que pôde ser alcançada mediante práticas de cooperação, cultura participativa e adoção sistemática de ações coletivas. Estas interações que ocorrem dentro do arranjo possuem uma estrutura de coordenação e governança que permite maior eficácia e eficiência no desempenho das atividades produtivas desenvolvidas.

No referido arranjo constatamos que as dimensões desta coordenação e governança possuem traços específicos e peculiares a essa forma de organização produtiva. Dentre estas dimensões, destacam-se formas de coordenação, tanto internas quanto externas, ao arranjo. Na posição de coordenação interna ao arranjo, há de se enfatizar o baixo grau de formalização do arranjo (a existência de contratos formais de associação), pois nenhum dos produtores entrevistados possui qualquer tipo de acordo e/ou contrato formal. E, em segundo lugar ressalta-se certa simetria no grau de centralização da coordenação do arranjo ou na tomada de decisões, isto é, uma certa paridade no processo decisório.

Estas particularidades podem ser verificadas pelos fortes laços interpessoais existentes no arranjo que foram favorecidos, ou melhor, foram conduzidos por fatores culturais, históricos e pela capacidade de reação das pessoas frente aos problemas e desafios da vida. Pois, conforme Amaral Filho (2002), a agricultura diferente de outros ramos de atividade, permite fixar as pessoas ao território ao mesmo tempo que cria relações de proximidade e de confiança entre os produtores, quando se trata de agricultura familiar atuando em estrutura de minifúndio, como é o caso do arranjo Pingo D’água. Da terra também surge outra instituição informal de coordenação, e de governança, que é o próprio território vivido pelos agricultores, representado pelas relações de propriedade, de posse e de afetividade com a terra. Outras instituições não menos importantes são a esperança e a auto-estima nutridas pelos sertanejos em relação à viabilidade da região semi-árida. Todos esses elementos formam o conjunto de instituições de coordenação interna do arranjo em questão. 
Estas características promovem uma boa governança do arranjo, pois norteiam as relações cooperativas entre os produtores, contribuindo com a formação de estratégias coletivas, facilitando as ações coordenadas das atividades econômicas, promovendo a troca aberta de informações e a aprendizagem coletiva. Desta maneira, este arranjo, onde as decisões são tomadas pelos produtores proporciona, oportunidades econômicas que não podem ser divorciadas do contexto social no qual estão inseridos.

Outros elementos importantes na composição da estrutura de coordenação e governança e de caráter externo ao arranjo ocorrem mediante a participação da Prefeitura de Quixeramobim, que promove os elementos institucionais, de âmbito publico, necessários ao bom desempenho das atividades do arranjo. O papel de destaque na atuação da Prefeitura diz respeito, principalmente, à habilidade na articulação político-institucional para atração dos parceiros, como as Universidades francesas e a Estadual do Ceará (UECE), bem como, o Governo do Estado representado pelas secretarias de agricultura irrigada (SEAGRI) e de desenvolvimento local e regional (SDLR), Banco do Nordeste Brasileiro (BNB) e o SEBRAE/Ce. Portanto, estes elementos, tanto exógenos quanto endógenos, criaram um ambiente institucional favorável modelando a estrutura social que contribuiu para a coordenação e governança dos esforços em conjunto de todos os agentes envolvidos em prol de seus interesses coletivos.

Estes mecanismos foram os pilares para difusão da inovação e processo de aprendizagem coletiva do arranjo Pingo d'Água, porque tais processos não estão sujeitos somente ao desempenho das organizações específicas, como empresas e instituições de pesquisa, mas também de como elas se relacionam entre si e com o setor governamental, para produção, distribuição e uso do conhecimento, em benefício da competitividade e para o desenvolvimento do arranjo em foco.

Vimos que a Prefeitura local tem sido essencial para a estruturação, ampliação, articulação e coordenação do arranjo. Entretanto, segundo Amaral Filho (2004), é importante dar prosseguimento às políticas públicas municipais voltadas para o desenvolvimento econômico, dentre as quais se encontram as ações direcionadas ao arranjo Pingo d'Água.

A continuidade destas ações se faz importante porque os produtores 
por intermédio da sua Associação, ainda não têm autonomia suficiente para manutenção da governança do arranjo, principalmente após o término do acordo de cooperação entre a Prefeitura de Quixeramobim e as universidades francesas e cearense, em 2003, necessitando, portanto, de uma forte aliança estratégica com a Prefeitura local para superar o desafio de se continuar gerando e experimentando inovações, sem o apoio imediato de instituições voltadas à pesquisa (AMARAL FILHO, 2004).

\section{Conclusões e sugestões}

No arranjo produtivo Pingo d'Água, com base na agricultura irrigada, localizado no vale do Forquilha em Quixeramobim, Ceará, constatamos o envolvimento de vários agentes de diversos segmentos com maior ou menor grau de participação. Estas parcerias estabelecem instrumentos importantes para a geração de fluxos de informações no processo inovativo, verificadas pela possibilidade de conhecimento de novos métodos de produção, bem como na disseminação da tecnologia de perfuração de poços. As conexões entre estes agentes ocorrem sob diversas formas de cooperação, manifestadas pela consciência coletiva dos produtores, representando uma importante opção para vencer os problemas da seca, bem como o baixo grau de capitalização e promover a competitividade destes produtores.

Tais ações ocorreram mediante a uma boa governança do arranjo orientando as relações cooperativas entre os produtores, colaborando com a formação de estratégias coletivas tanto no âmbito da produção e inovação organizacional, de produto e processo, quanto nas estratégias coletivas de mercado. Esta boa governança facilita as ações coordenadas, promovendo resultados positivos para os produtores e, conseqüentemente, garantindo, o bom desempenho competitivo deste, além de promover o desenvolvimento do arranjo.

Alguns problemas, porém, foram identificados, dentre os quais se destaca a inexistência de centros de treinamento continuados e adequados para qualificação tanto dos produtores quanto da mão-de-obra, a ausência de laboratórios de pesquisa, desenvolvimento e testes de novos produtos, a carência de linhas de crédito mais adequadas à realidade dos produtores, no que diz respeito ao financiamento para capital 
de giro e as barreiras relacionadas à garantia ou aval dos empréstimos aos pequenos produtores que não possuem garantias reais.

Com base nos dados e análise apresentadas sobre a dinâmica interna desse arranjo, sugerimos algumas propostas capazes de minimizar esses problemas, quais sejam:

a) dinamizar as decisões de interesse dos produtores, solidificando a sustentabilidade do arranjo, como a promoção da cooperação entre os mesmos, no intuito de solucionar problemas do setor como forma de fortalecer a Associação.

b) compatibilizar a estrutura das organizações, tais como Serviço Nacional de Aprendizagem Industrial (SENAI), Centros Vocacionais Tecnológicos (CVT's) e Centro de Ensino Tecnológico (CENTEC), às necessidades de treinamento e capacitação do arranjo;

c) articular a aquisição de um Box na CEASA para os produtores do arranjo Pingo d’Água. O intuito desta medida é viabilizar um melhor local para a comercialização dos produtos, bem como a criação de um ambiente que fortaleça o intercâmbio entre os produtores e clientes; e

d) criar uma conexão com as informações sobre os preços de mercado das frutas e hortaliças da CEASA de Fortaleza por meio de um boletim informativo divulgado pela emissora de rádio local.

Essas propostas não implicam, necessariamente, melhorias imediatas na estruturação e desenho do arranjo, mas, se implementadas, poderão estimular no médio e longo prazo, um avanço na competitividade dos produtores, dado que acentuarão as relações cooperativas e minimizarão os problemas existentes. Portanto, o arranjo Pingo d’Água de agricultura irrigada de Quixeramobim encontra-se em fase de maturação, mas, podemos concluir que existem alguns ganhos de eficiência coletiva, segundo a terminologia apresentada no início deste trabalho, e alguns desafios devem ser enfrentados para garantir a evolução e sustentabilidade deste arranjo. O exemplo, mais importante, entretanto, e que deve ficar em nossas reflexões diz respeito ao fato de que o arranjo produtivo Pingo d'Água ter sido uma prova viva de que, com um pouco de organização social e de vontade dos atores locais articulados entre si, e com outras instituições formais ou informais, é possível mudar a realidade desfavorável daquelas famílias que vivem da agricultura de sequeiro no sertão semi-árido cearense. 


\section{Referências bibliográficas}

ALBAGLI, S. e BRITO, J. (orgs). Glossário de arranjos produtivos locais: Projeto Políticas Promoção de Arranjos Produtivos Locais de MPME. Rio de Janeiro: UFRJ/IE/redeSist, 2003. Arquivo disponível em $<$ www.ie.ufrj.br/redesist > acesso em: Out.2003.

AMARAl FILHO, J do. Arranjo Produtivo Pingo D'água, Quixeramobim, Ceará. Disponível em < http://www.ie.ufrj.br/rede 2004> acesso em: Dez.2004.

É negócio ser pequeno, mas em grupo. In desenvolvimento em Debate, painéis do desenvolvimento brasileiro II, BNDES, Rio de Janeiro, RJ, 2002.

AMARAL FILHO, J. do.; AMORIM, M.A.; ROCHA, G.; RABELO, D.; MOREIRA, M.V.C.; ARAÚJO, M.R. de.; SCIPIÃO, T. Núcleos e Arranjos Produtivos Locais: casos do Ceará. Disponível em: < www.ie.ufrj.br/ redesist $>$. acesso em Nov.2003.

AMORIM, M, A. e MOREIRA, M.V.C; IPIRANGÁ, A.S.R. A construção de uma metodologia de atuação nos arranjos produtivos locais (APL'S) no Estado do Ceará: um enfoque na formação e fortalecimento do capital social e governança. Interações: Revista Internacional de Desenvolvimento Local, Campo Grande, v. 4, n. 9, p.25-34, set. 2004.

ARAÚJO, A.M.M.; FUCK JÚNIOR, S.C. Uma leitura geográfica de Mudanças culturais no semi-árido provocadas por mudanças técnicas. Revista da Casa da Geografia de Sobral, Sobral, v. 2/3, n. 1, p.71-79, 2000/2001.

CAMPOS, R.; CARIO, S.; NICOLAU, J. A. e VARGAS, G. Aprendizagem por interação: pequenas empresas em sistemas produtivos e inovativos locais. In: LASTRES, H.M.M. et al.. Pequena Empresa: Cooperação e Desenvolvimento Local. Relume Dumará, Rio de Janeiro,2003.

CAMPOS, R.R. e NICOLAU, J.A. Questionário e procedimentos para trabalho de campo da pesquisa de micro e pequenas empresas em arranjos produtivos locais. Disponível em <www.ie.ufrj.br/redesist>. Acesso em Set.2003

CASSIOLATO, J. E e LASTRES, H.M.M. O foco em Arranjos Produtivos e Inovativos Locais de Micros e Pequenas Empresas. In: LASTRES, 
H.M.M. et al.. Pequena Empresa: Cooperação e Desenvolvimento Local. Relume Dumará, Rio de Janeiro,2003.

CASSIOLATO, J. E e SZAPIRO, M. Uma caracterização de Arranjos Produtivos Locais de Micro e Pequenas Empresas. In: LASTRES, H.M.M. et al.. Pequena Empresa: Cooperação e Desenvolvimento Local. Relume Dumará, Rio de Janeiro,2003.

FOUNTAIN, J. Social capital: a key enabler of innovation. In: BRASCOMB, L. KELLER, J. (ED). Investing in innovation: towards a consensus strategy for federal technology policy. Cambridge. MIT, 1997.

FELDMAN, T. R. e ASSAF, S. Social capital: conceptual frameworks and empirical evidence, an annotated bibliografhy. world brank. Working paper $n^{\circ} 5,1999$. Arquivo disponível em < http://www.worldbank.org/ > acesso em: Out.2002.

IPECE - Instituto de Pesquisa e Estratégia Econômica do Ceará. Site: $<$ www.ipece.ce.gov.br > acesso em: Out.2003

LA ROVERE, R.; Estratégias competitivas em sistemas de micro, pequenas e médias empresas: a importância da gestão de informações. In: LASTRES, H.M.M. et al.. Pequena Empresa: Cooperação e Desenvolvimento Local. Relume Dumará, Rio de Janeiro,2003.

PUTNAM, R.D. Comunidade e democracia: a experiência da Itália moderna. Rio de Janeiro, FGV, 1996.

REDESIST- Rede de Pesquisa em Sistemas Produtivos e Inovativos Locais. < www.ie.ufrj.br/redesist > acesso em: Out.2003

RAFAEL NETO, J. Arranjo produtivo de confecções de Frecheirinha, Ceará. Dissertação (Mestrado profissional)-CAEN/UFC, 76f. 2003.

SCHOMMER, P.C. Projeto Pingo D’água. In: BARBOZA, H.B. e SPINK, P. (orgs). 20 Experiências de gestão pública e cidadania, São Paulo: Programa gestão pública e cidadania, 2002.

SOUZA, D. L. R de. Arranjo produtivo de calçados do Cariri, Ceará. Dissertação (Mestrado profissional)-CAEN/UFC, 97f. 2003.

Recebido em maio de 2005 e revisto em maio de 2006 